American Journal of Applied Sciences 6 (4): 745-751, 2009

ISSN 1546-9239

(C) 2009 Science Publications

\title{
Optimization of the Performance of Single-Phase Capacitor-Run Induction Motor
}

\author{
Mahdi Salman Alshamasin \\ Department of Mechatronics, Faculty of Engineering Technology, \\ Al-Balqa'a Applied University, P.O. Box 15008, Amman 11134, Jordan
}

\begin{abstract}
The aim of the study was to suggest optimal solution for the impact of harmonics on the performance of Capacitor-Run Motor (CRM), the most commonly used single-phase motor. Therefore, investigations were carried out over the entire slip from no-load condition up to the locked-rotor condition, for harmonics of various orders in the case of using Pulse-Width Modulation (PWM) speed control. The investigations gave the ability to optimize the performance of CRM by choosing the appropriate parameters of the PWM inverter. Mathematical model for CRM supplied from voltage source contained harmonics was presented. The work was conducted by using a digital computer simulation (MATLAB software).
\end{abstract}

Key words: Single-phase capacitor-run motor, main phase, auxiliary phase, harmonics, motor balance, static characteristics, MATLAB, motor performance

\section{INTRODUCTION}

Over the past few years, the number and effect of single-phase nonlinear harmonic-producing devices connected to electrical drive systems have increased significantly. This has resulted in non-sinusoidal currents propagated through the supply network causing distortion in the supply voltage. Therefore, the supply voltage is taking non-sinusoidal forms which cause unbalance and asymmetry between motor phases ${ }^{[1]}$.

Capacitor-Run Motors (CRMs) are widely used in fields where there are no three-phase lines (domestic and agricultural) and in low-powered loads ${ }^{[2]}$. Many areas have only single-phase power, which means that a large number of single phase motors is used. In such cases, it is important to minimize the energy consumption by enhancing the performance of these motors. Also, enhancing the motor performance results in minimizing the power line transformer and distribution losses ${ }^{[3]}$. CRMs suffer from heating resulting from unbalance of motor operation ${ }^{[4]}$ caused by harmful harmonics. The search presented in the study was devoted to study the effect of the number of pulses upon the harmonics on the output of the PWM inverter and, hence, the performance of the motor by using symmetrical component method for the motor modeling and MATLAB software for the simulation. Knowing the harmful harmonics leads to an easy treatment of heating. Power consumption, efficiency and, displacement power factor for various level-orders of harmonics were investigated. Also, the total harmonic distortion of current $\left(\mathrm{THD}_{\mathrm{I}}\right)$, total harmonic distortion of voltage $\left(\mathrm{THD}_{\mathrm{V}}\right)$ and true power factor versus slip were plotted.

\section{EQUIVALENT CIRCUIT}

Harmonics cause the deformation of the sinusoidal form of the motor supply voltage. Therefore, the produced field in the CRM has a rectilinear, an elliptical or a circular form, depending on the balance of the motor ${ }^{[5]}$. The non-sinusoidal stator voltage can be resolved into fundamental and harmonic components by Fourier analysis $^{[6]}$. For a symmetrical waveform, only the odd harmonics will be presented. Utilizing the symmetrical components method, the unbalanced motor variables can be decomposed into positive (forward) sequence components and negative (backward) sequence components. So, the slip at the hth harmonic for the positive and negative sequences, respectively, can be given as ${ }^{[2]}$ :

$$
\begin{gathered}
\mathrm{S}_{(1) \mathrm{h}}=\frac{\mathrm{h} \omega_{0} \mp \omega_{\mathrm{r}}}{\mathrm{h} \omega_{0}}=1 \mp \frac{1-\mathrm{S}_{1}}{\mathrm{~h}} \\
\mathrm{~S}_{(2) \mathrm{h}}=2-\mathrm{S}_{(1) \mathrm{h}}
\end{gathered}
$$

where, the number of harmonic $\mathrm{h}=1,3,5,7, \ldots . \mathrm{n}$.

For the mostly used single-phase CRM with the principle circuit as in Fig. 1 and the equivalent circuit as in Fig. 2, the harmonic current of the positive and negative sequences can be calculated as ${ }^{[7]}$ : 


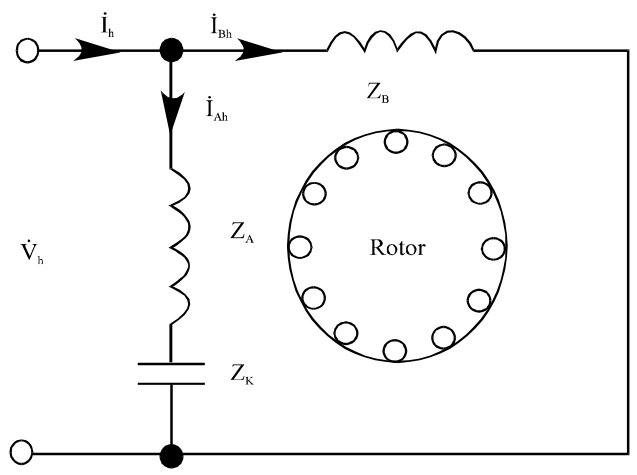

Fig. 1: Circuit diagram of the CRM

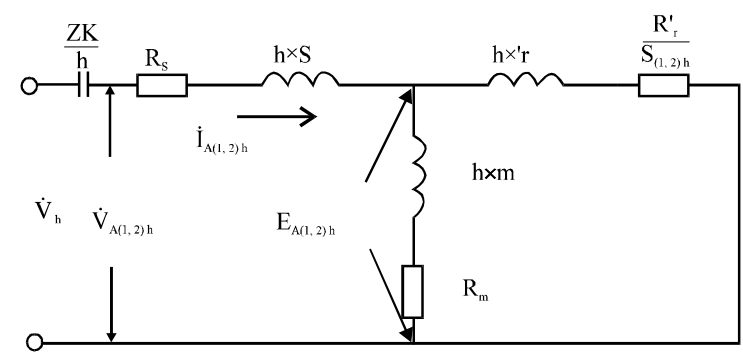

Fig. 2a: Equivalent circuit of CRM for the auxiliary phase

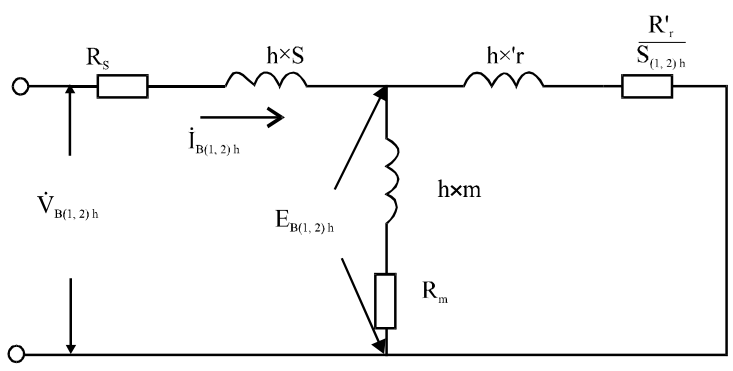

Fig. 2b: Equivalent circuit of the CRM for the main phase.

$$
\dot{\mathrm{I}}_{(1,2) \mathrm{h}}=\frac{\dot{\mathrm{V}}_{(1,2) \mathrm{h}}}{\mathrm{Z}_{(1,2) \mathrm{h}}}
$$

where, positive (forward) and negative (backward) sequence impedance of the hth harmonic can be calculated from the equivalent circuit as ${ }^{[8]}$ :

$$
\begin{aligned}
& Z_{(1,2) \mathrm{h}}=r_{(1,2) \mathrm{h}}+j X_{(1,2) \mathrm{h}}= \\
& \sqrt{r_{(1,2) \mathrm{h}}^{2}+X_{(1,2) \mathrm{h}}^{2}} e^{\text {jarctan }} \frac{X_{(1,2) \mathrm{h}}}{r_{(1,2) \mathrm{h}}}
\end{aligned}
$$

Where:

$$
\begin{gathered}
r_{(1,2) h}=R_{S}+\frac{\left(R_{m}+\frac{R_{r}^{\prime}}{S_{(1,2) h}}\right)\left(R_{m} \frac{R_{r}^{\prime}}{S_{(1,2) h}}-h^{2} X_{m} X_{r}^{\prime}\right)}{\left(R_{m}+\frac{R_{r}^{\prime}}{S_{(1,2) h}}\right)^{2}+\left(h X_{m}+h X_{r}^{\prime}\right)^{2}}+ \\
\frac{\left(h X_{m}+h X_{r}^{\prime}\right)\left(h R_{m} X_{r}^{\prime}+\frac{h X_{m} R_{r}^{\prime}}{S_{(1,2) h}}\right)}{\left(R_{m}+\frac{R_{r}^{\prime}}{S_{(1,2) h}}\right)^{2}+\left(h X_{m}+h X_{r}^{\prime}\right)^{2}}
\end{gathered}
$$

$$
\begin{aligned}
X_{(1,2) \mathrm{h}}=h X_{S}+\frac{\left(R_{m}+\frac{R_{r}^{\prime}}{S_{(1,2) h}}\right)\left(h R_{m} X_{r}^{\prime}+h X_{m} \frac{R_{r}^{\prime}}{S_{(1,2) h}}\right)}{\left(R_{m}+\frac{R_{r}^{\prime}}{S_{(1,2) h}}\right)^{2}+\left(h X_{m}+h X_{r}^{\prime}\right)^{2}}- \\
\frac{\left(h X_{m}+h X_{r}^{\prime}\right)\left(\frac{R_{m} R_{r}^{\prime}}{S_{(1,2) h}}-h^{2} X_{m} X_{r}^{\prime}\right)}{\left(R_{m}+\frac{R_{r}^{\prime}}{S_{(1,2) h}}\right)^{2}+\left(h X_{m}+h X_{r}^{\prime}\right)^{2}}
\end{aligned}
$$

\section{MATHEMATICAL MODEL OF THE CRM}

For the single-phase CRM with the principle circuit as in Fig. 1, the positive (forward) sequence torque is defined as:

$$
\begin{aligned}
\mathrm{T}_{(1) \mathrm{h}}=\mathrm{T}_{\mathrm{A}(1) \mathrm{h}}+\mathrm{T}_{\mathrm{B}(1) \mathrm{h}}= & \frac{\mathrm{E}_{\mathrm{A}(1) \mathrm{h}}^{2} \frac{\mathrm{R}_{\mathrm{rA}}^{\prime}}{\mathrm{S}_{(1) \mathrm{h}}}}{\omega_{0 \mathrm{~h}}\left[\left(\frac{\mathrm{R}_{\mathrm{rA}}^{\prime}}{\mathrm{S}_{(1) \mathrm{h}}}\right)^{2}+\left(\mathrm{hX_{ \textrm {rA } } ^ { \prime }}\right)^{2}\right]} \\
& +\frac{\mathrm{E}_{\mathrm{B}(1) \mathrm{h}}^{2} \frac{\mathrm{R}_{\mathrm{rB}}^{\prime}}{S_{(1) \mathrm{h}}}}{\omega_{0 \mathrm{~h}}\left[\left(\frac{\mathrm{R}_{\mathrm{rB}}^{\prime}}{\mathrm{S}_{(1) \mathrm{h}}}\right)^{2}+\left(h X_{\mathrm{rB}}^{\prime}\right)^{2}\right]}
\end{aligned}
$$

Similarly, the negative (backward) sequence torque is defined as: 


$$
\begin{aligned}
\mathrm{T}_{(2) \mathrm{h}}=\mathrm{T}_{\mathrm{A}(2) \mathrm{h}}+\mathrm{T}_{\mathrm{B}(2) \mathrm{h}}= & \frac{\mathrm{E}_{\mathrm{A}(2) \mathrm{h}}^{2} \frac{\mathrm{R}_{\mathrm{rA}}^{\prime}}{2-\mathrm{S}_{(1) \mathrm{h}}}}{\omega_{0 \mathrm{~h}}\left[\left(\frac{\mathrm{R}_{\mathrm{rA}}^{\prime}}{2-\mathrm{S}_{(1) \mathrm{h}}}\right)^{2}+\left(\mathrm{hX} \mathrm{X}_{\mathrm{rA}}^{\prime}\right)^{2}\right]} \\
& +\frac{\mathrm{E}_{\mathrm{B}(2) \mathrm{h}}^{2} \frac{\mathrm{R}_{\mathrm{rB}}^{\prime}}{2-\mathrm{S}_{(1) \mathrm{h}}}}{\omega_{0 \mathrm{~h}}\left[\left(\frac{\mathrm{R}_{\mathrm{rB}}^{\prime}}{2-S_{(1) \mathrm{h}}}\right)^{2}+\left(h X_{\mathrm{rB}}^{\prime}\right)^{2}\right]}
\end{aligned}
$$

The motor torque is given by:

$$
\mathrm{T}_{\mathrm{h}}=\mathrm{T}_{(1) \mathrm{h}}-\mathrm{T}_{(2) \mathrm{h}}
$$

and the motor output power and input power are:

$$
\begin{aligned}
\mathrm{P}_{2 \mathrm{~h}}=\mathrm{T}_{\mathrm{h}} \omega_{\mathrm{h}} & =\mathrm{T}_{\mathrm{h}} \omega_{0 \mathrm{~h}}\left(1-\mathrm{S}_{(1) \mathrm{h})}\right. \\
\mathrm{P}_{1 \mathrm{~h}} & ==\mathrm{V}_{\mathrm{h}} \mathrm{I}_{\mathrm{h}} \cos \phi_{\mathrm{h}}
\end{aligned}
$$

So, the power factor is:

$$
\cos \phi_{\mathrm{h}}=\frac{\mathrm{P}_{1 \mathrm{~h}}}{\mathrm{~V}_{\mathrm{h}} \mathrm{I}_{\mathrm{h}}}
$$

and the efficiency is:

$$
\eta_{h}=\frac{P_{2 h}}{P_{1 h}}
$$

Total distortion factors of voltage and current, the true power factor and the displacement power factor,respectively, are ${ }^{[9-11]}$ :

$$
\begin{gathered}
\mathrm{THD}_{\mathrm{V}}=\frac{\sqrt{\sum_{\mathrm{h}=2}^{\infty} \mathrm{V}_{\mathrm{h}}{ }^{2}}}{\mathrm{~V}_{1}} \times 100 \%, \\
\mathrm{THD}_{\mathrm{I}}=\frac{\sqrt{\sum_{\mathrm{h}=2}^{\infty} \mathrm{I}_{\mathrm{h}}{ }^{2}}}{\mathrm{I}_{1}} \times 100 \% \\
\mathrm{PF}_{\text {true }}=\frac{\mathrm{P}_{\text {lavg }}}{\mathrm{V}_{1} \mathrm{I}_{\mathrm{l}}} \times \\
\frac{\sqrt{1+\left(\mathrm{THD}_{\mathrm{V}} / 100\right)^{2}} \sqrt{1+\left(\mathrm{THD}_{\mathrm{I}} / 100\right)^{2}}}{\mathrm{PF}_{\text {disp }}}=\cos \phi_{1}=\frac{\mathrm{P}_{\mathrm{l}(1)}}{\mathrm{V}_{1} \mathrm{I}_{1}}
\end{gathered}
$$

The true efficiency determined as:

$$
\eta_{\text {true }}=\frac{\mathrm{P}_{2 \text { avg }}}{\mathrm{P}_{\text {lavg }}}=\frac{\sum_{\mathrm{h}=1}^{\infty} \mathrm{P}_{2 \mathrm{~h}}}{\sum_{\mathrm{h}=1}^{\infty} \mathrm{P}_{1 \mathrm{~h}}}
$$

\section{SIMULATION AND RESULTS}

The entire work was conducted by using a digital computer simulation (MATLAB software). The specifications of the motor used in the simulation were as follows:

Motor type KDO 83-4, $V_{\mathrm{n}}=380 \mathrm{~V}, \quad \mathrm{P}_{\mathrm{n}}=45 \mathrm{~kW}$, $\mathrm{I}_{\mathrm{L}}=137 \mathrm{~A}, \quad \mathrm{I}_{\mathrm{B}}=77 \mathrm{~A}, \quad \mathrm{I}_{\mathrm{A}}=100 \mathrm{~A}, \quad \mathrm{~V}_{\mathrm{K}}=540 \mathrm{~V}$, $\mathrm{n}=1430 R P M, \quad \mathrm{C}=590 \mu \mathrm{F}, \quad \mathrm{T}_{\mathrm{n}}=312$ N.m, $\quad \mathrm{K}=1$, $S_{n}=0.0465, \quad \cos \varphi=0.985, \quad$ efficiency $(\eta)=87.9 \%$, $\mathrm{R}_{\mathrm{S}}=0.065 \mathrm{Ohm}, \quad \mathrm{R}_{\mathrm{r}}^{\prime}=0.26 \mathrm{Ohm}, \quad \mathrm{X}_{\mathrm{S}}=0.25 \mathrm{Ohm}$, $\mathrm{X}_{\mathrm{r}}^{\prime}=0.12 \mathrm{Ohm}, \mathrm{R}_{\mathrm{m}}=0.14 \mathrm{Ohm}, \mathrm{X}_{\mathrm{m}}=6.12 \mathrm{Ohm}$. data:

The plots are obtained for the following inverter

DC supply voltage of the inverter $=600 \mathrm{~V}$, frequency of the output voltage $=50 \mathrm{~Hz}$, modulation index $=0.895$, the frequency of the carrier signal $=500$, 2000 and $3500 \mathrm{~Hz}$.

An attempt was made to obtain the optimal frequency of the inverter to get the best motor performance. The PWM mechanism is shown in Fig. 3 together with the output waves for $f_{c}=500 \mathrm{~Hz}$. For all analyses, exact values were calculated and are shown in Table 1. The harmonic analyses of PWM output for different values of carrier frequency are shown in Fig. 4a-5c.

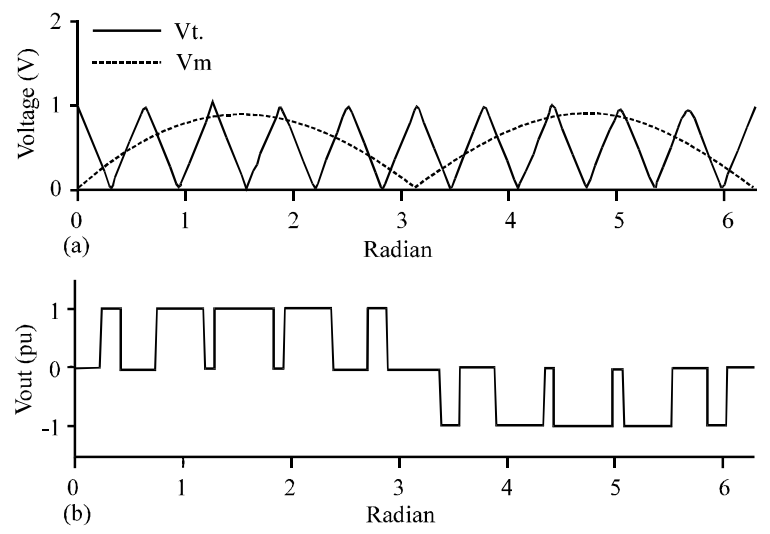


Fig. 3: Technique of PWM, (a): Triangular carrier (Vt) and modulating sine waves $(\mathrm{Vm})$ and $(\mathrm{b})$ : PWM output

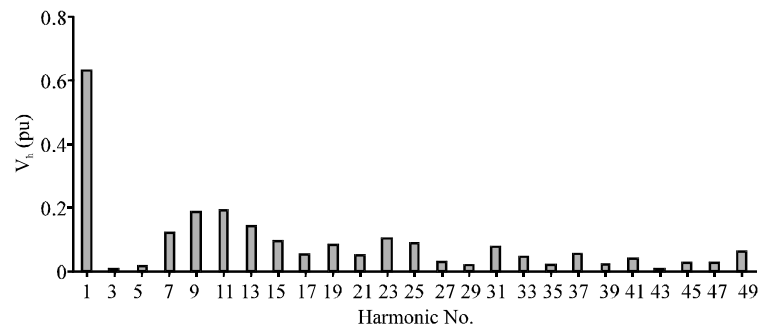

Fig. 4a: Harmonic voltages, $\mathrm{f}_{\mathrm{c}}=500 \mathrm{~Hz}$

Table 1: Effects of harmonics on the motor at rated speed

\begin{tabular}{lllllllll}
\hline $\begin{array}{l}\text { Frequency } \\
(\mathrm{Hz})\end{array}$ & $\begin{array}{l}\text { Fundamental } \\
\text { voltage(V) }\end{array}$ & $\begin{array}{l}\text { Inverter } \\
\text { output }(\mathrm{V})\end{array}$ & $\mathrm{THD}_{\mathrm{V}}$ & THD $_{\mathrm{I}}$ & PFdis. & PFtrue & EFfund. & EFtrue \\
\hline 500 & 379.35 & 449.1 & 0.63366 & 0.97476 & 1 & 0.6317 & 0.91279 & 0.86712 \\
2000 & 380 & 424 & 0.49498 & 0.19804 & 0.9937 & 0.87366 & 0.91279 & 0.91084 \\
3500 & 379.82 & 379.83 & 0.00685 & 0.00969 & 0.9916 & 0.9916 & 0.91279 & 0.91278 \\
\hline
\end{tabular}

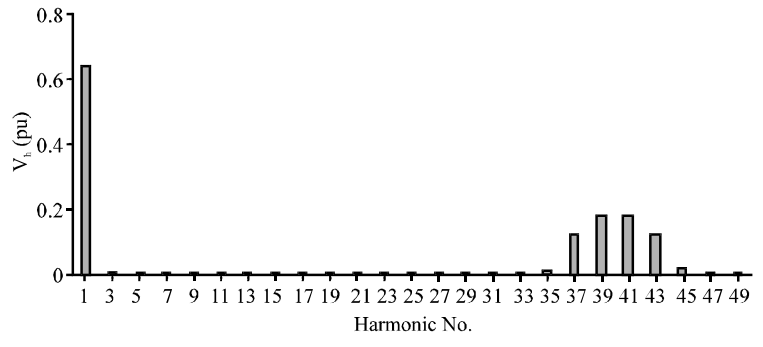

Fig. 4b: Harmonic voltages, $\mathrm{f}_{\mathrm{c}}=2000 \mathrm{~Hz}$

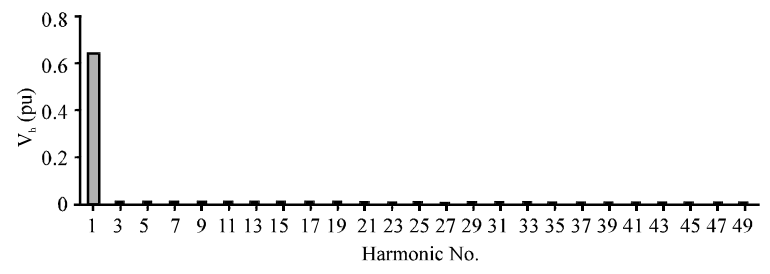

Fig. 4c: Harmonic voltages, $f_{c}=3500 \mathrm{~Hz}$

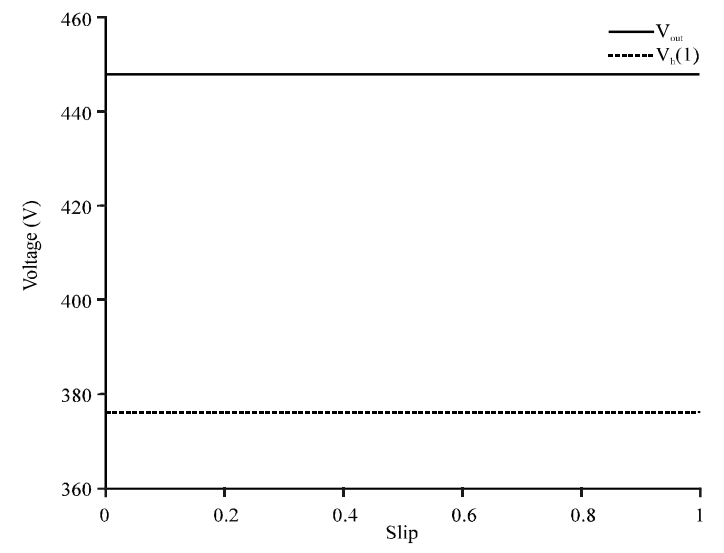

Fig. 5a: Output voltage of the inverter and fundamental harmonic voltage, $\mathrm{f}_{\mathrm{c}}=500 \mathrm{~Hz}$

These figures show that when $f_{c}=500 \mathrm{~Hz}$, the significant amplitude of lower order harmonics is included in the PWM output voltage. As $\mathrm{f}_{\mathrm{c}}$ is increased, these harmonics decrease to negligible values. Really, hence $f_{c}$ determines the number of pulses in the halfcycle of the PWM output (m), the small $\mathrm{m}$ obtained by $\mathrm{f}_{\mathrm{c}}=500 \mathrm{~Hz}$ is rich of lower level harmonics.

Figure 6a-6c show the contribution of above fundamental harmonics to the rms value of the

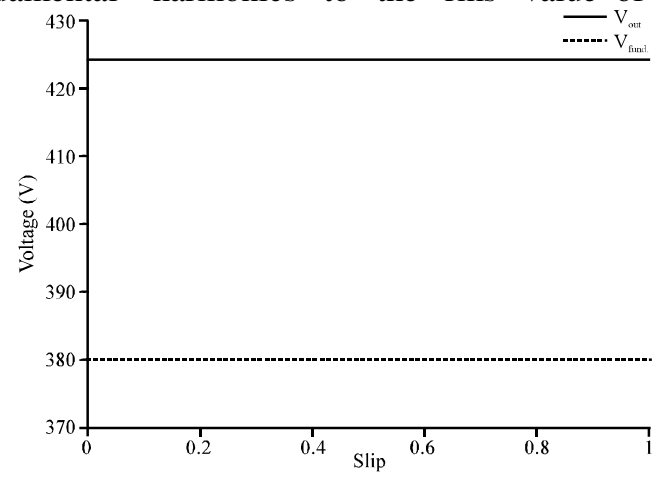

Fig. 5b: Output voltage of the inverter and fundamental harmonic voltage, $\mathrm{f}_{\mathrm{c}}=2000 \mathrm{~Hz}$ 
Am. J. Appl. Sci., 6 (4): 745-751, 2009

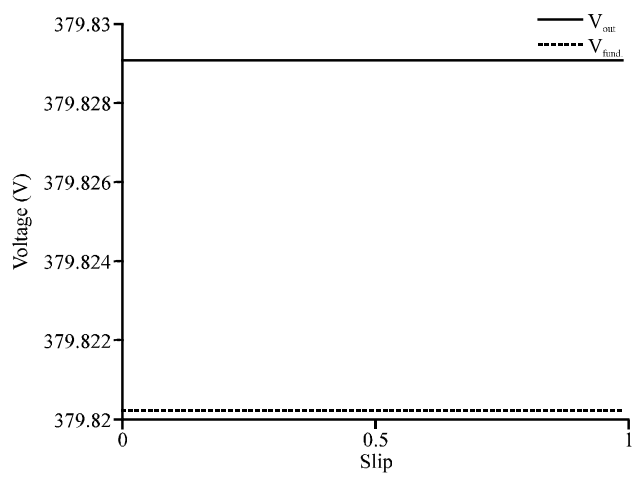

Fig. 5c: Output voltage of the inverter and fundamental harmonic voltage, $f_{c}=3500 \mathrm{~Hz}$

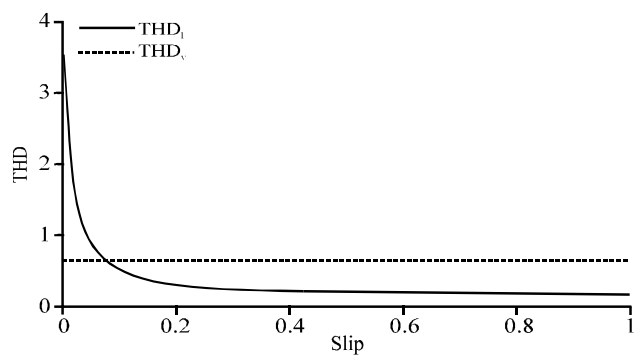

Fig. 6a: Total harmonic distortion of current and voltage, $\mathrm{f}_{\mathrm{c}}=500 \mathrm{~Hz}$

fundamental one. It is obvious that increasing $f_{c}$ decreases the total harmonic distortion of voltage $\mathrm{THD}_{\mathrm{V}}$ and current $\mathrm{THD}_{\mathrm{I}}$ to negligible values but for small $\mathrm{m}$

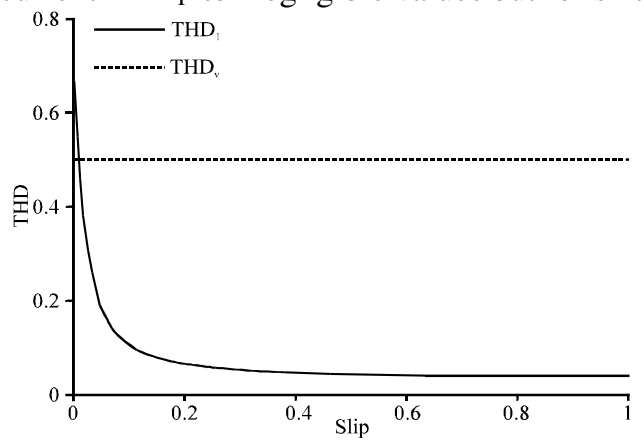

Fig. 6b: Total harmonic distortion of current and voltage, $\mathrm{f}_{\mathrm{c}}=2000 \mathrm{~Hz}$

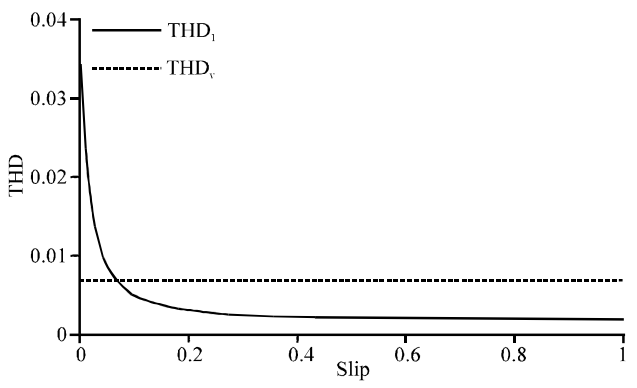

Fig. 6c: Total harmonic distortion of current and voltage, $\mathrm{f}_{\mathrm{c}}=3500 \mathrm{~Hz}$

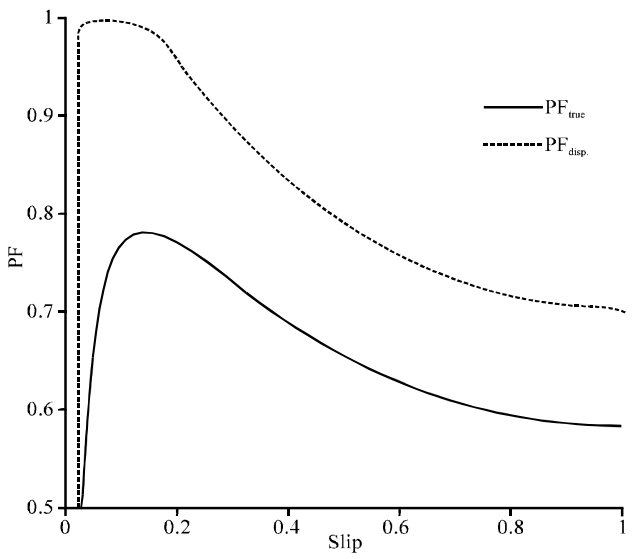

Fig. 7a: True power factor and displacement power factor, $\mathrm{f}_{\mathrm{c}}=500 \mathrm{~Hz}$

(say at $f_{c}=500 \mathrm{~Hz}$ ), $\mathrm{THD}_{\mathrm{V}}$ and $\mathrm{THD}_{\mathrm{I}}$ values are not acceptable.

Power Factor (PF) and efficiency are shown in Fig. 7a-8c. As seen from these Figures, the motor performance for small $\mathrm{m}\left(\mathrm{f}_{\mathrm{c}}=500 \mathrm{~Hz}\right)$ is the worst, because of asymmetry of stator phases (elliptical field form) due to the presence of lower order harmonics in

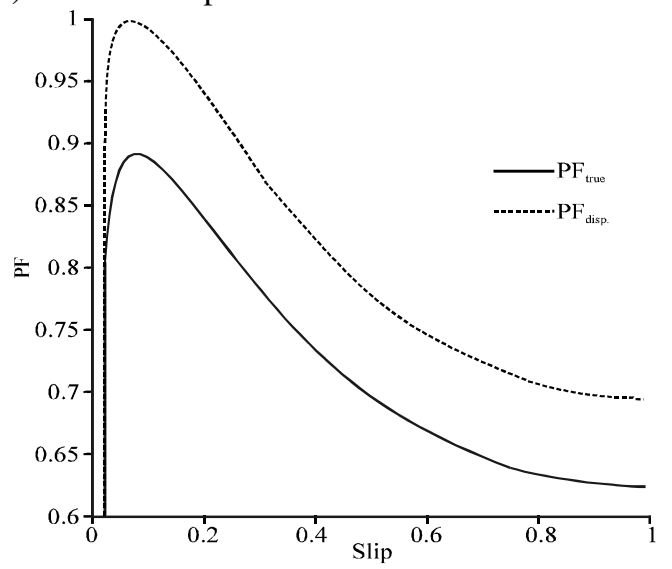


Fig. 7b: True power factor and displacement power factor, $\mathrm{f}_{\mathrm{c}}=2000 \mathrm{~Hz}$

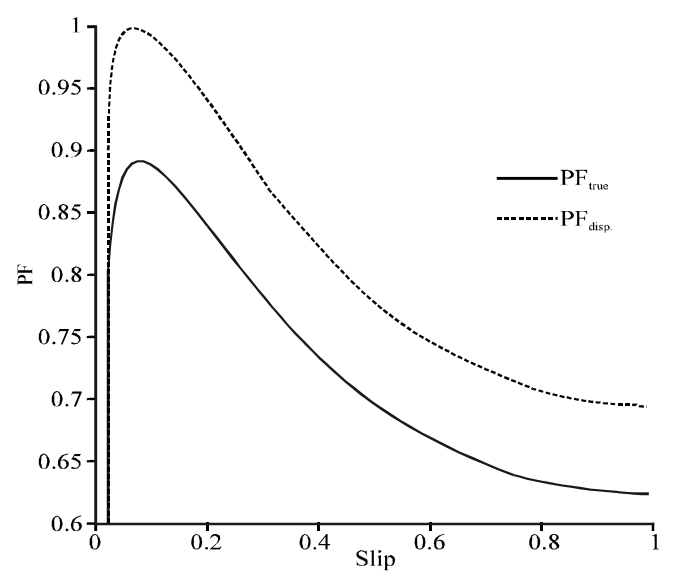

Fig. 7c: True power factor and displacement power factor, $\mathrm{f}_{\mathrm{c}}=3500 \mathrm{~Hz}$

the motor terminal voltage. For $f_{c}=2000 \mathrm{~Hz}$, lower order harmonics are absent, but the performance of the motor is not optimal, because higher order harmonics are present and they cause losses in the iron core and copper wires due to the hysteresis and skin effect. For large $m\left(f_{c}=3500 \mathrm{~Hz}\right)$, the performance is the best and no contribution of harmonics in the motor consumed power and output power is observed.

As it is well known, CRMs suffer from the imbalance of the stator currents due to the elliptical field form, as slip changes its value. So, the presence of harmonics will deteriorate the motor balance and cause increased copper lossses. Therefore, it is great importance to minimize the influence of harmonics on the the motor performance via techniques which can eliminate or reduce the distortion caused by harmoics.

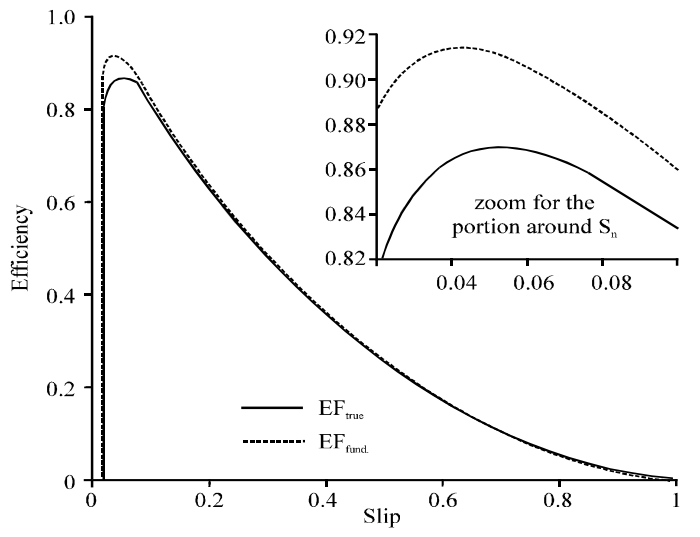

Fig. 8a: True efficiency and efficiency caused by the fundamental harmonic, $\mathrm{f}_{\mathrm{c}}=500 \mathrm{~Hz}$

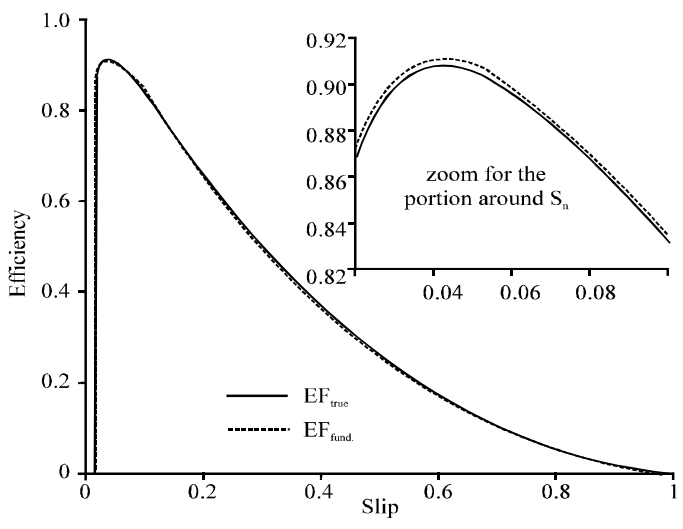

Fig. 8b: True efficiency and efficiency caused by the fundamental harmonic, $\mathrm{f}_{\mathrm{c}}=2000 \mathrm{~Hz}$

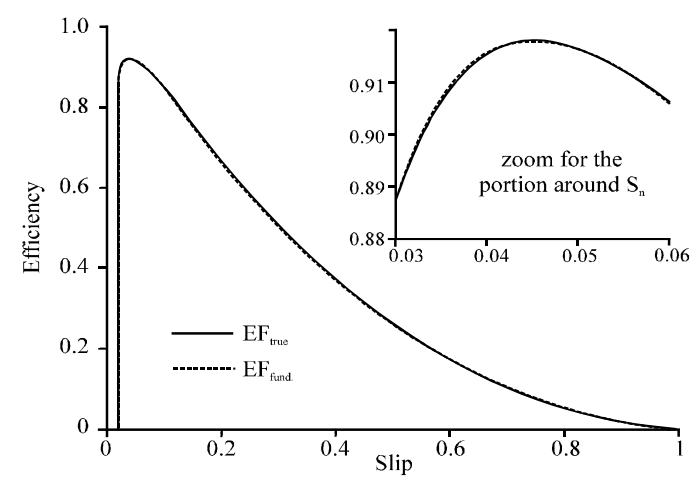

Fig. 8c: True efficiency and efficiency caused by the fundamental harmonic, $\mathrm{f}_{\mathrm{c}}=3500 \mathrm{~Hz}$

\section{CONCLUSION}

The study presented mathematical model for a CRM exposed to harmonics. The influence of harmmonics on the power factor,efficiency, effective output voltage of the inverter and current distortion was discussed. As shown from the figures, the harmonic current distortion level tended to fall into the low, medium and high levels depending upon the slip value.

Results showed that lower order harmonics can be neglected by increasing the carrier frequency and hence the number of pulses in the output of PWM to a convenient one. It was shown that the carrier frequency $\mathrm{f}_{\mathrm{c}}=2000 \mathrm{~Hz}$ was suitable to get the negligible influence of the lower order harmonics on the motor performance. If no filters are used, the carrier frequency should be increased to a convenient value such as $f_{c}=$ 
$3500 \mathrm{~Hz}$ to neglect the effects of both lower order and higher order harmonics on the motor performance.

Based on the results of study, the optimal carrier frequency to eliminate the influence of both lower order and higher order harmonics was found to be $3500 \mathrm{~Hz}$ which created 35 pulses in the half-cycle of the PWM output. So, the PWM technique is recommended to neglect the effect of harmonics on the performance of single-phase CRMs without the need to use filters or additional devices.

\section{REFERENCES}

1. Eguiluz, L. et al., 2000. Performance analysis of a three-phase induction motor under non-sinusoidal and unbalanced condition. IEEE Trans. Ind. Applicat., 36: 1-46.

2. Usmanhodjaief, N.M., 1980. Methods for controlling the speed of the capacitor-run singlephase induction motor, Energy, Moscow.

3. Dubey, G.K., 2002. Fundamental of Electric Drives. Narosa Publishing House, India.

4. Letenmaier, T.A., D.W. Novotny and T.A. Lipo, 1991. Single-phase induction motor with an electronically controlled capacitor. IEEE Trans. Ind. Appli., 27: 38-43.
5. Alshamasin, M.S., 2004. Balancing the operation of stator phases of the capacitor-run single-phase induction motors at variable frequencies. J. Eng., T.B. Centre for Science and Technology, dec.,14: 173-180.

6. Ekram, S. and B. Sarkar, 2004. Effects of harmonics on PWM inverter fed induction machines. J. Instn. Eng. India-Pt EL, 85: 1-12.

7. Miller, T.J.E., M. Popescu, M. Mcglip, G. Strappazzon, N. Trivillin and M. Santarossa, 2003. Asynchronous performance analysis of a single-phase capacitor-start, capacitor-run permanent magnet motor. IEEE Trans. Ind. Applicat., 39: 1021-1030.

8. Alshamasin, M.S., 2005. Improving the performance of a capacitor-run single-phase motor by using a labVIEW program. J. Inst. Math. Comput. Sci., 16: 137-148.

9. Narayanan, G. and T. Ranganathan, 2005. Analytical evaluation of harmonic distortion in PWM ac drives using the notion of stator flux ripple. IEEE Trans. Power Elect., 20: 466-474

10. Wildi, T., 2006. Electric Machines, Drives and Power Systems. Pearson Education, New Jersey.

11. Singh, G., 2005. A research survey of induction motor operation with non-sinusoidal supply wave forms, Elect. Power Syst. Res., 75: 200-213. 